\title{
Statistical interpretation of environmental influencing parameters on COVID-19 during the lockdown in Delhi, India
}

\author{
Amit Awasthi $^{1}$ D $\cdot$ Aditi Sharma ${ }^{2} \cdot$ Prabhjot Kaur $^{3} \cdot$ Balakrishnaiah Gugamsetty $^{4}$. \\ Akshay Kumar ${ }^{5}$
}

Received: 9 August 2020 / Accepted: 18 September 2020 / Published online: 25 September 2020 (c) Springer Nature B.V. 2020

\begin{abstract}
The novel coronavirus disease is known as COVID-19, which is declared as a pandemic by the World Health Organization during March 2020. In this study, the COVID-19 connection with various weather parameters like temperature, wind speed, and relative humidity is investigated and the future scenario of COVID-19 is predicted based on the Gaussian model (GM). This study is conducted in Delhi, the capital city of India, during the lowest mobility rate due to strict lockdown nationwide for about two months from March 15 to May 17, 2020. Spearman correlation is applied to obtain the interconnection of COVID-19 cases with weather parameters. Based on statistical analysis, this has been observed that the temperature parameter shows a significant positive trend during the period of study. The number of confirmed cases of COVID-19 is fitted with respect to the number of days by using the Gaussian curve and it is estimated on the basis of the model that maximum cases will go up to 123,886 in number. The maximum number of cases will be observed during the range of $166 \pm 36$ days. It is also estimated by using the width of the fitted GM that it will take minimum of 10 months for the complete recovery from COVID-19. Additionally, the linear regression technique is used to find the trend of COVID-19 cases with temperature and it is estimated that with an increase in temperature by $1{ }^{\circ} \mathrm{C}, 30$ new COVID-19 cases on daily basis will be expected to observe. This study is believed to be a preliminary study and to better understand the concrete relationship of coronavirus, at least one complete cycle is essential to investigate. The laboratory-based study is essential to be done to support the present field-based study. Henceforth, based on preliminary studies, significant inputs are put forth to the research community and government to formulate thoughtful strategies like medical facilities such as ventilators, beds, testing centers, quarantine centers, etc., to curb the effects of COVID-19.
\end{abstract}

Keywords Coronavirus · COVID-19 · Exposure studies · Gaussian model · Pandemic · Weather parameters

Electronic supplementary material The online version of this article (https://doi.org/10.1007/s1066 8-020-01000-9) contains supplementary material, which is available to authorized users.

Amit Awasthi

awasthitiet@gmail.com

Extended author information available on the last page of the article 


\section{Introduction}

The world is facing a challenge on how to cope with the effects of coronavirus disease (COVID-19) which is first identified in the Chinese city named Wuhan in late December 2019 (Ahmadi et al. 2020). World Health Organization (WHO) named this disease as COVID-19 in February 2020. COVID-19 is named after coronavirus-2 SARS-CoV-2 which causes acute respiratory problems and the suffix19 denotes its triggering year 2019 (Sohrabi et al. 2020). It is important to understand that the discovery of coronaviruses in human and animals is made in the 1930s (Zhong et al. 2003). Among all coronaviruses, only seven types are responsible for causing diseases in humans. Out of these, four viruses are responsible for symptoms of the common cold but the other three are responsible for severe lung infections like pneumonia, etc. These three viruses are severe acute respiratory syndrome (SARS-CoV), Middle East respiratory syndrome (MERS-CoV-2), and SARSCoV-2, i.e., the current pandemic known as COVID-19 triggered in years 2002, 2012, and 2019, respectively (Zheng et al. 2020).

Coronaviruses are tiny in size having a diameter in the range between 65 and $125 \mathrm{~nm}$ that contains a single-stranded RNA as a nucleic material. The alpha, beta, gamma, and delta are the subgroups of the coronaviruses family (Shereen et al. 2020). Chinese researchers initially named this novel virus as the Wuhan coronavirus 2019 and thereafter named as a novel coronavirus (2019-nCov). The International Committee on Taxonomy of Viruses (ICTV) called the virus as SARS-CoV-2 and the illness associated with it as COVID-19 (Cui et al. 2019; Lai et al. 2020; Shereen et al. 2020). Similar to the common flu, coronavirus transmits through droplets from person to person when a disease-ridden person coughs or sneezes near other people. It is also observed that COVID-19 enters the body through mouth, nose, or eyes as and when touched by an infected hand which was in contact with the contagious surface. Clinical signs of MERS and SARS are similar to those of COVID19 (Chow 2020; Lai et al. 2020; Zhong et al. 2003). The common symptoms include body ache, fever, lung infection, difficulty in breathing, tiredness, etc. It is observed that risk of casualty due to COVID-19 increases among the elderly group and people having chronic health conditions. Elder subjects and children, in general, are more sensitive to respiratory symptoms(Agarwal et al. 2010, 2014; Awasthi et al. 2010, 2017). COVID-19 is a major concern these days in every country because there is no exact cure so far. Precautions are sought to be the prevailing means to protect from this pandemic prone virus infection. People with mild illness/symptoms are treated by self-isolation (quarantine) and basic medication. The duration of self-isolation depends on the intensity of the symptoms which is observed from the testing results of patients. Since many factors may trigger the COVID19 cases, in the present work, the aim is to study the interconnection of meteorological parameters and COVID-19 cases.

After the announcement of COVID-19 as a pandemic by WHO in March 2020, different types of investigations increased at a faster pace (Arora et al. 2020; Gautam and Hens 2020a, b; Gautam and Trivedi 2020; Rajput et al. 2020). Along with other studies on COVID-19, researchers also focused to find the relationships between weather conditions and coronavirus (Bashir et al. 2020; Jahangiri et al. 2020; Menebo 2020; Şahin 2020; Shi et al. 2020; Tosepu et al. 2020). A portion of the investigations even stated that a warm climate may reduce the vulnerability of the virus (Gupta et al. 2020). Different countries around the world announced a lockdown to make some strategic plans, to reduce and to control the effects of COVID-19. Besides, in India, the first lockdown was announced on March 25, 2020 with more consecutive lockdowns ahead. Lockdown possessed a serious 
effect on the economy of countries but air quality and environment improved (Gautam 2020; Jain and Sharma 2020; Metya et al. 2020; Nakada and Urban 2020), because most industries and transportation halted during the period of lockdown. In this work, the study period considered for the investigation is the lockdown period, so that the relationship of meteorological parameters with COVID-19 cases is studied in a controlled manner that may help in better anticipation of the relationship between the virus and weather parameters. Along with this, efforts have been carried out to predict the maximum number of COVID-19 cases, peak time, and maximum duration of this pandemic. For this purpose, statistical approach is used and available data points are fitted based on the exponential and Gaussian curve.

\section{Methods}

\subsection{Study area}

The study area selected is Delhi, Capital city of India, which lies in the northern part of India located between $28.7041^{\circ} \mathrm{N}, 77.1025^{\circ} \mathrm{E}$ and has a land cover of $1484 \mathrm{~km}^{2}$ and a population of about 19 million (Fig. 1) ("Delhi Location Map" 2020). In Delhi, the first case of COVID-19 is reported on March 2, 2020, and up to June 30, 2020, 87,360 infected people are reported and consisting of 2742 deaths ("Delhi Location Map" 2020).

\subsection{Data collection}

The information with respect to the weather conditions is collected from Wunderground, which fetches its data from the National Weather Service (NWS), comprising of around 250,000 climate stations (Wunderground 2020). The information of the number of COVID19 patients for Delhi state has been taken from covid19india.org, a site that updates its information in real time from state press announcements, official (CM, Health Ministry) handles, PBI, Press Trust of India, ANI reports, and Ministry of Health and Family Welfare (“COVID19 DELHI DATA” 2020).

Confirmed cases of COVID-19 represent the sum of all active, recovered, and deceased number up to that particular day, while daily cases are the difference of two consecutive days of confirmed cases.

\subsection{Study period}

The study period for this research is for two months from March 15, 2020 to May 17, 2020. This duration is decided because it comprised the period of the first three phases of lockdown in India. During the lockdown, sources of harmful gases and particulate matters were reduced dramatically, because most of the industries and major movement of vehicles were halted due to which air quality is improved up to a remarkable extent throughout the world (Broomandi et al. 2020; Gautam and Hens 2020a; Gautam and Trivedi 2020; Jain and Sharma 2020; Li et al. 2020; Zhang et al. 2020). During the current study period, a major movement of people is restricted due to lockdown, and henceforth other transmission factors of COVID-19 are targeted to nullify, reduce, or control up to a certain level. 


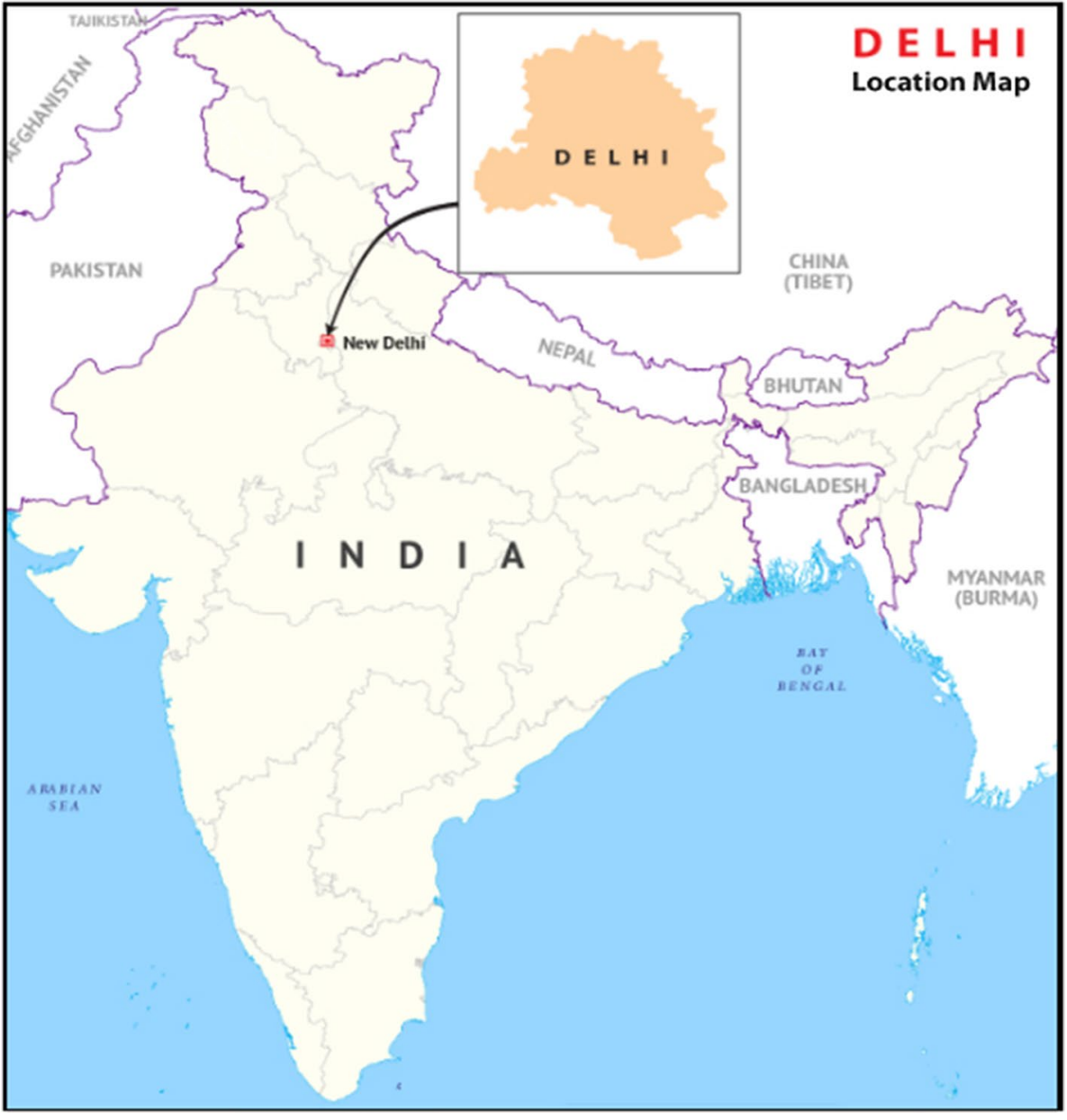

Fig. 1 Location of Delhi in Indian context ("Delhi Location Map" 2020)

\subsection{Statistical analysis}

The statistical analysis is carried out using the Statistical Package for Social Sciences (SPSS) (Windows version 15). The standard method of linear regression is applied to calculate the association between different meteorological parameters and COVID-19 cases. Origin software is used for plotting different types of graphs and fitting the data for extrapolation. A nonlinear exponential curve is used to fit the two months data during a rigorous lockdown period. For the prediction of future scenarios of COVID-19 cases, a Gaussian model (GM) is developed. GM is used because epidemics like COVID-19 are firstly exponential in nature and sooner or later saturation in number of cases will be observed and show a bell-shaped curve like the Gaussian function. Three independent parameters of fitted GM, a peak time, an amplitude, and a width of the Gaussian curve (GC), are used to predict valuable information. Using the GM, the forecast for further course of the COVID-19 pandemic is possible statistically from the three independent descriptors. All 
statistical significance tests are two-tailed and with confidence index/level at $95 \%$. A level of $p$ value $\leq 0.05$ is considered to be statistically significant.

\section{Results}

Figure 2 represents the daily variation in different weather parameters from March 15 to May $17,2020 . T_{\mathrm{Max}}, T_{\mathrm{Min}}$, and $T_{\mathrm{Av}}$ represent the maximum, minimum, and average temperature, respectively. Humidity ${ }_{\mathrm{Av}}$ represents average Humidity and $\mathrm{WS}_{\mathrm{Av}}$ represents average wind speed on a particular day. Average wind speed varies between $4 \pm 1$, relative humidity varies between $61 \pm 11$, maximum temperature varies between $34 \pm 4$, minimum temperature varies between $21 \pm 4$, and average temperature varies between $27 \pm 3$. To check the trend in different weather parameters, the linear trend is drawn between weather parameters as a dependent variable and time, i.e., on different dates as an independent variable and shown in Fig. 3.

There is no clear trend observed in the cases of average wind speed, whereas a negative trend is observed in relative humidity. The minimum, maximum, and average value of temperature show a positive trend. The value of $R^{2}$ indicates that the strength level is maximum in case of average temperature value. Overall there is no significant decrease or increase with time in case of wind speed, whereas temperature value increases during the study period.

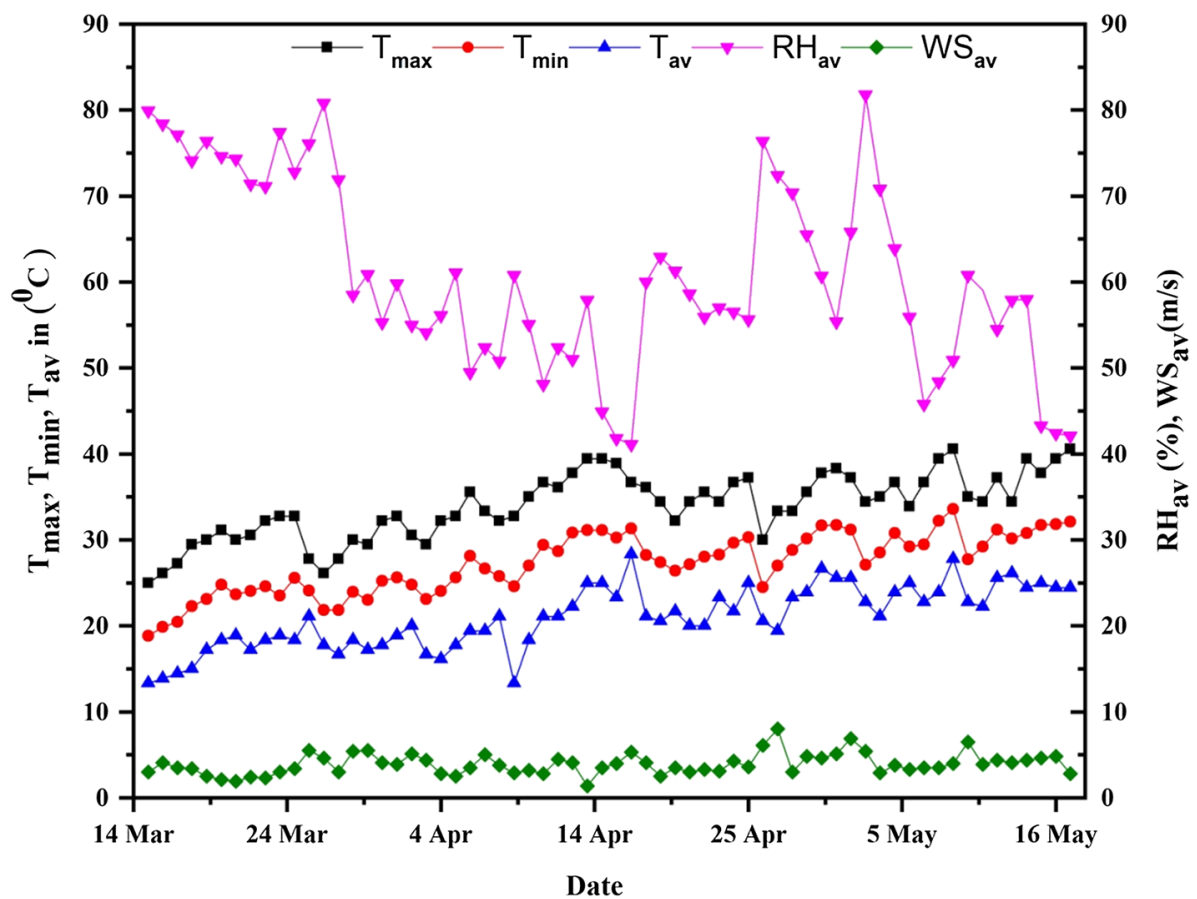

Fig. 2 Daily variation in maximum, minimum, and average temperature and average humidity and wind speed 


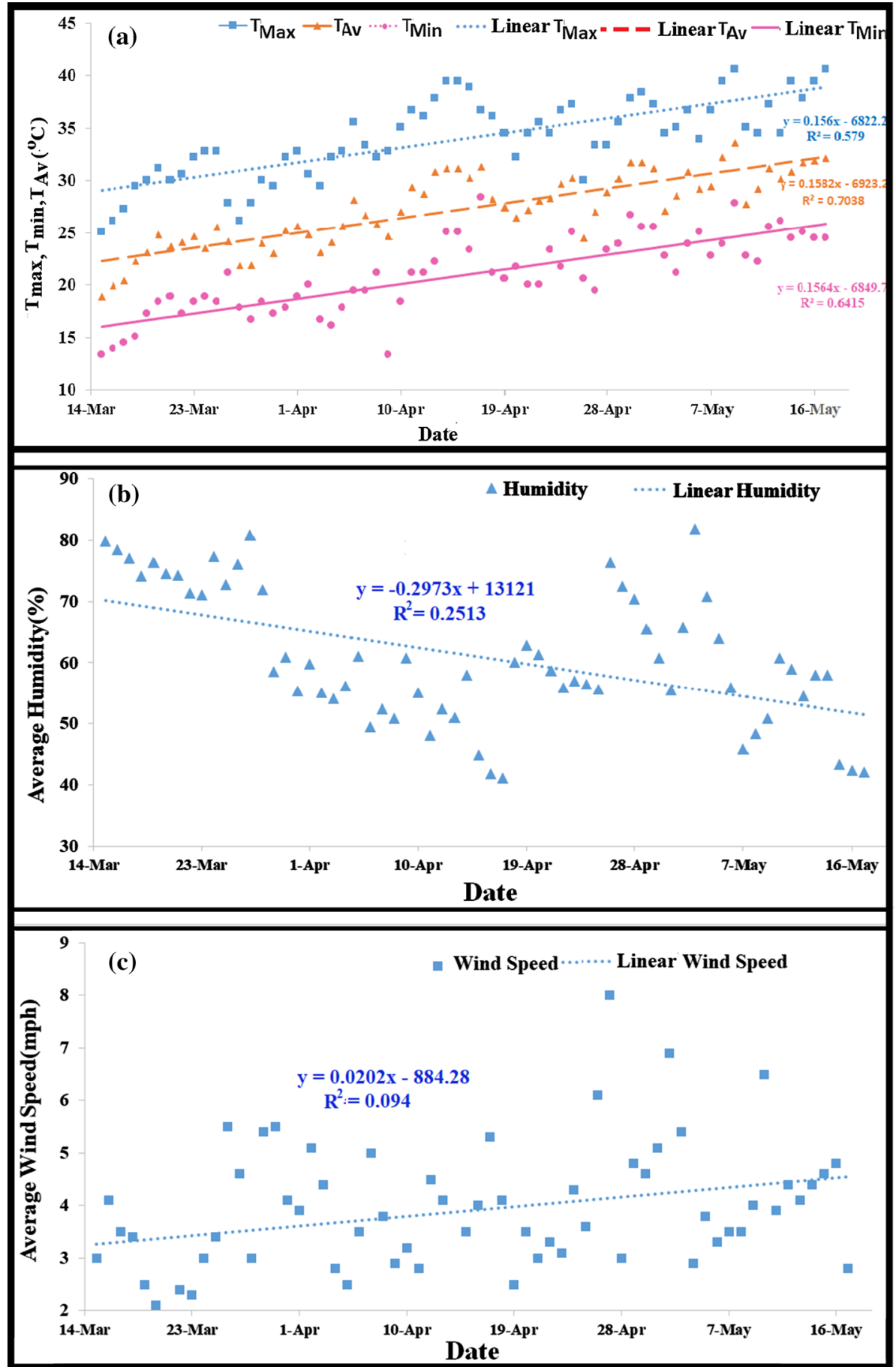

Fig. 3 Trend of a maximum, minimum, and average temperature, $\mathbf{b}$ average humidity, $\mathbf{c}$ average wind speed with respect to date 
Table 1 Correlation matrix between confirmed COVID cases and weather parameters

\begin{tabular}{lllllll}
\hline & $T_{\max }\left({ }^{\circ} \mathrm{C}\right)$ & $T_{\mathrm{av}}\left({ }^{\circ} \mathrm{C}\right)$ & $T_{\min }\left({ }^{\circ} \mathrm{C}\right)$ & Humidity $_{\mathrm{av}}(\%)$ & $\mathrm{WS}_{\mathrm{av}}(\mathrm{mph})$ & Confirmed \\
\hline$T_{\max }\left({ }^{\circ} \mathrm{C}\right)$ & 1 & & & & & \\
$T_{\text {av }}\left({ }^{\circ} \mathrm{C}\right)$ & 0.956 & 1 & & & & \\
$T_{\min }\left({ }^{\circ} \mathrm{C}\right)$ & 0.819 & 0.915 & 1 & & & \\
Humidity $_{\mathrm{av}}(\%)$ & -0.666 & -0.656 & -0.499 & 1 & & \\
$\mathrm{WS}_{\mathrm{av}}(\mathrm{mph})$ & $0.110^{\mathrm{a}}$ & $0.190^{\mathrm{a}}$ & $0.311^{\mathrm{a}}$ & $-0.124^{\mathrm{a}}$ & 1 & \\
Confirmed & 0.761 & 0.831 & 0.818 & -0.460 & $0.310^{\mathrm{a}}$ & 1 \\
\hline
\end{tabular}

Correlation is significant at the 0.01 level;

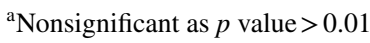

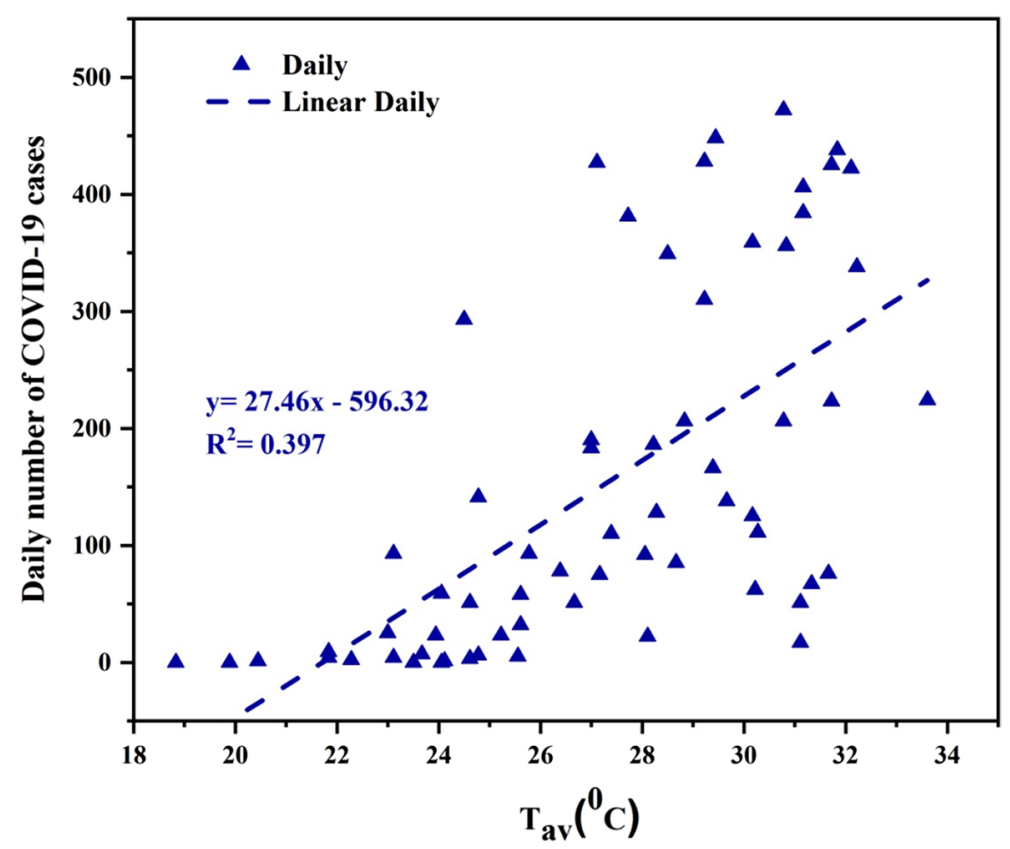

Fig. 4 Trend of daily new COVID-19 cases with respect to average temperature

For further clarity, the correlation table is drawn for weather parameters and the number of confirmed cases. It is observed from the table that the average temperature is significantly correlated with the number of COVID-19 cases. Table 1 indicates that based on the correlation coefficient and $p$ value, COVID-19 cases show a nonsignificant relationship with wind speed. Slope, correlation coefficients, and significance level indicate that average temperature is strongly connected with the COVID-19 cases in comparison with other weather parameters. Finally, it is calculated based on linear regression, by taking the number of daily COVID-19 cases as dependent and daily average temperature as the independent variable and trend is shown in Fig. 4. Based on the linear trend and linear regression technique, it is observed that with the increase in the 
value of average temperature by $1{ }^{\circ} \mathrm{C}$, there is a significant $(<0.05)$ increase in 30 new cases of COVID-19. This observation is only based on statistical analysis, and the exact scientific reason or justification behind this type of observation further needs sophisticated laboratory-based study.

In Fig. 5, the daily variation in COVID-19 cases (blue dot) is plotted from March 15 to May 17, 2020. These data points are then fitted to different types of curves, and the best fit curve is obtained for a nonlinear exponential equation and the equation is shown in Fig. 5. The equation formulated for the initial set of data is as follows:

$$
y=-6.17+98.5 * \exp ^{\left(\frac{x+26}{19}\right)} ; R^{2}=0.997
$$

The best fitted line $\left(R^{2}=0.997\right)$ in Fig. 5 on the basis of the nonlinear fitting, strongly indicates that the number of confirmed COVID-19 cases increase exponentially during the study period. The exponential growth rate is the main concern of intellectuals like researchers, doctors, and strategists to think about possible solutions. To predict the future scenario of COVID-19, this is not appropriate to use an exponential equation, because an exponential growth represents a continuous increase, whereas in the pandemic scenario, the number of cases will indeed increase rapidly up to certain days or months, afterward the value will start to decrease after forming a peak. It is interesting to estimate the peak value and time coverage of COVID-19 cases. For this purpose, a predicted model other than an exponential equation is required.

Keeping in view the expected behavior of COVID-19 cases, the available 64 data points are fitted and plotted based on the single Gaussian curve as shown in Fig. 6.

The fitted model equation is of the form; $y=y_{0}+\frac{A}{W \sqrt{\pi / 2}} \exp ^{-2\left(\frac{x-x_{0}}{W}\right)^{2}}$

The fitted Gaussian model statistically predicts that the number of COVID-19 cases initially increases continuously until a peak is formed at 123,886 number of cases. Based on

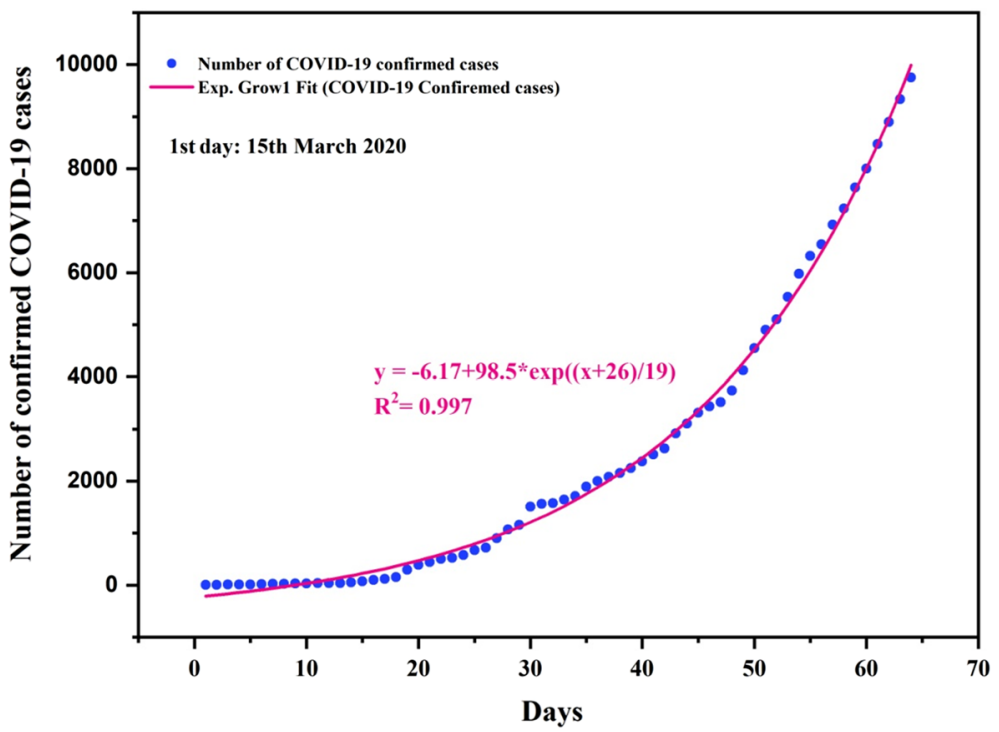

Fig. 5 Daily variation in confirmed COVID-19 cases 


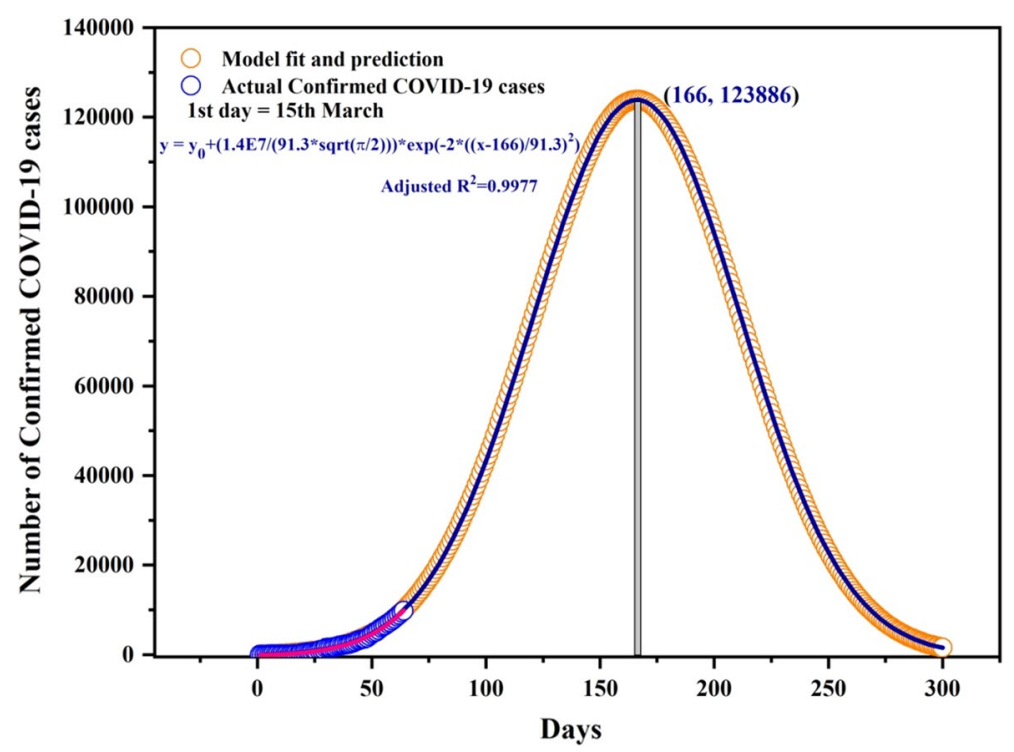

Fig. 6 Gaussian plot on the basis of the number of confirmed cases

the fitted GM, it is predicted that the maximum number of cases is observed during the time range of $166.15 \pm 36$ days. Based on the number of days calculated from the peak value of the fitted model, it is estimated that the number of cases will increase maximum up to the second week of October 2020, afterward a decrease in the number of cases may be observed. The fitted model also indicates that it may take about 300 days to touch the minimum number of COVID-19 cases yet again. This predicted observation or estimation is assumed to be true based on the fitted statistical Gaussian equation when only one wave of COVID-19 cases is considered.

\section{Discussion}

Undoubtedly, the COVID-19 pandemic has shown a lower mortality rate in comparison with previously observed viruses like SARS, MERS, etc. But its exponential growth is a serious concern all around the world. This concern among the people will be the maximum until the development and availability of vaccination of COVID-19. Previous studies show that the strength of similar viruses like SARS reduces at a higher temperature and relative humidity (Lin et al. 2006). But in the present study, the number of cases of COVID-19 has increased with the increase in temperature.

In Fig. 7, the legend shape of a square, triangle, and circle denotes three weather parameters namely temperature, humidity, and wind speed, respectively. Figure 7 contains three quarters representing three types of variation of COVID-19, i.e., positive, negative, and neutral trend with different weather parameters as observed in the state-of-the-art studies. Sahin (2020) and Shi et al. (2020) observed a negative relationship of temperature with COVID-19, whereas in contrary, Bashir et al. (2020) and Tosepu et al. (2020) observed a positive relationship. For another meteorological parameter, humidity, Bashir et. al. (2020) found a negative correlation with COVID-19, and Tosepu et al (2020) showed a positive 


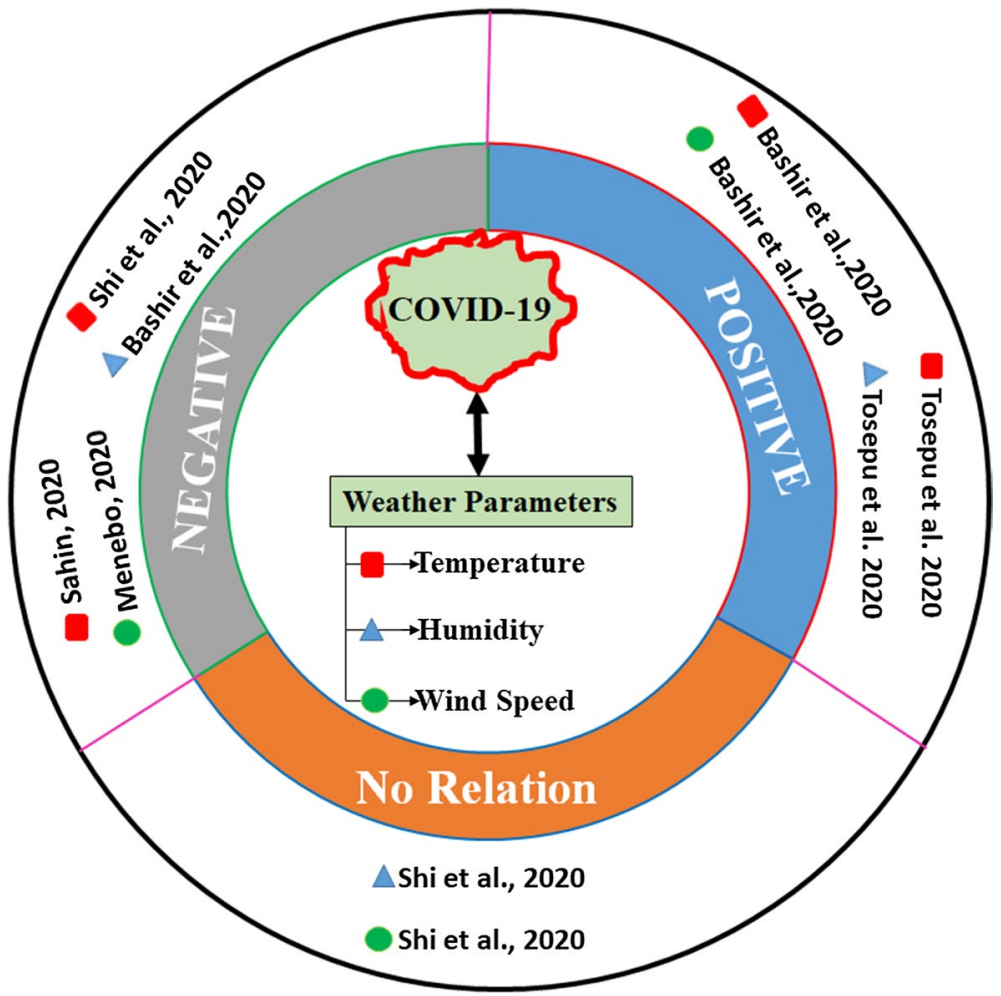

Fig. 7 Relationship of COVID-19 with respect to temperature, humidity, and wind speed

relationship. The study conducted by Shi et al. (2020) showed no significant relationship between humidity and COVID-19 cases. The third weather parameter wind speed showed negative, positive, and no relation with COVID-19 by Menebo et al. (2020), Bashir et al. (2020), and Shi et al. (2020), respectively.

Jahangiri, et al. (2020) provided a conclusive statement that no scientific evidence is found to confirm that warm ambient temperature reduces the number of COVID cases. These studies along with the present preliminary study have certain limitations like population sensitivity, virus confrontation, and cleanliness of population and precaution taken by the population related to COVID-19. The study duration for the state-of-the-art studies shown in Fig. 6 is maximum for up to three months, thus categorize these under preliminary indicative studies. All these are indicated as field-based studies that provide conclusions based on statistical analysis which need to be supported by laboratory-based experiments.

The first case of COVID-19 in Delhi is observed in March 2020. As per the climate of Delhi, November-January are the coldest months of the capital city, and afterward, the temperature increases, and March is supposed to be the initial month of the summer season. This may be a coincidence that COVID-19 started to spread in Northern India during the mid of March and similarly temperature also started to increase from March onward with the arrival of the summer season. The availability of testing kits increased with time leading to more testing, which is supposed to be one of the reasons for more diagnoses 
for the number of COVID-19 cases. The variation in COVID-19 cases in winter or cold temperature is still needed to be observed. This is supposed to be one of the drawbacks of the study, i.e., if the study period could have been for at least six months including both winter and summer season, then better relational results with temperature could be drawn. So this is not confirmed that it is the temperature that is responsible for an increase in the number of cases with time or it is just coincidental due to the availability of a large number of the testing kit. Besides, it is too early to provide a conclusion about the relationship of COVID-19 with temperature. However, our results show that with the rise in temperature, the number of COVID-19 cases has increased dramatically. Although, this is also not confirmed that these cases have either been triggered by temperature or just coincidental. To achieve/obtain more reliable results, one complete cycle of COVID-19 need to be observed as in India winter season was over just before the arrival of COVID-19 in Delhi.

More strategic and rigorous studies of persistent data are required for a better conclusion. If the studies in which temperature has a negative relation with the COVID cases are believed to be precise, then this is more challenging for Delhi or all over the world where winter season is yet to come in the coming months. This indicates that upcoming months are tougher for those regions where winter season is commencing because in winter season usually due to cold weather conditions, respiratory diseases are easily triggered. Therefore, more care and strategies are needed to be designed by government agencies to reduce the effect of COVID-19 because GM extrapolates that it will take 300 days to recover from COVID-19 cases.

\section{Conclusions}

The weather parameters are significant to consider the transmission of communicable diseases. This preliminary study shows a positive significant relationship of COVID-19 with temperature and a negative relationship of COVID-19 with relative humidity. Based on the statistical approach of the linear regression technique, this is estimated that 30 new cases of COVID-19 are observed for every $1{ }^{\circ} \mathrm{C}$ rise in temperature. However, this is not supported by the $R^{2}$ value. Moreover, there is no scientific evidence that these numbers are triggered by weather parameters like temperature or just coincidental.

To understand the threshold of virus transmission and survival, more rigorous and robust studies are essential. For conclusive and concrete remarks, at least one complete cycle of COVID-19 is required for investigation. However, the present study along with state-of-the-art studies clearly shows a significant exponential increase in COVID-19 cases with time which is a serious concern for everyone. The exponential growth of COVID-19 cases is observed only in the initial stage which shows peak value after a certain time, hence the exponential fitting of data for prediction is not an accurate approach. Therefore, the GC is used to fit and extrapolate the data, which is used to estimate the number and date of the peak value. Based on the fitted GM, number of cases increases up to 123,886 in number, which will go maximum up to the second week of October 2020. Based on the width of GM, COVID-19 cases will be controlled in a minimum of 300 days, starting from March 15, 2020 and extending up to January 2021. Hence, this study is considered as one of the inputs for the researchers and government agencies to formulate some thoughtful strategies to control and reduce the effects of COVID-19. This study proposed to the government that more planned and vigorous arrangements in terms of infrastructure, health facilities, and financial support are required as the predicted results of GM show an 
extended number of COVID-19 cases in the near future. The extrapolated information from GM including maximum number, peak time, and maximum time will provide a basic idea to the government about the requirement of medical facilities such as ventilators, beds, testing centers, quarantine centers, etc.

\section{Compliance with ethical standards}

Conflict of interest The authors of this manuscript declare no conflict of interest.

\section{References}

Agarwal, R., Awasthi, A., Mital, S. K., Singh, N., \& Gupta, P. K. (2014). Statistical model to study the effect of agriculture crop residue burning on healthy subjects. Mapan-Journal of Metrology Society of India, 29(1), 57-65. https://doi.org/10.1007/s12647-013-0070-0.

Agarwal, R., Awasthi, A., Mittal, S., Singh, N., \& Gupta, P. K. (2010). Effects of air pollution on respiratory parameters during the wheat-residue burning in Patiala. Journal of Medical Engineering and Technology, 34(1), 23-28. https://doi.org/10.3109/03091900903261258.

Ahmadi, M., Sharifi, A., Dorosti, S., Jafarzadeh Ghoushchi, S., \& Ghanbari, N. (2020). Investigation of effective climatology parameters on COVID-19 outbreak in Iran. Science of the Total Environment, 729, 138705. https://doi.org/10.1016/j.scitotenv.2020.138705.

Arora, A. S., Rajput, H., \& Changotra, R. (2020). Current perspective of COVID-19 spread across South Korea: Exploratory data analysis and containment of the pandemic. Environment, Development and Sustainability. https://doi.org/10.1007/s10668-020-00883-y.

Awasthi, A., Hothi, N., Kaur, P., Singh, N., \& Chakraborty, and M., Bansal, S., (2017). Elucidative analysis and sequencing of two respiratory health monitoring methods to study the impact of varying atmospheric composition on human health. Atmospheric Environment, 171, 32-37.

Awasthi, A., Singh, N., Mittal, S., Gupta, P. K., \& Agarwal, R. (2010). Effects of agriculture crop residue burning on children and young on PFTs in North West India. Science of the Total Environment, 408(20), 4440-4445. https://doi.org/10.1016/j.scitotenv.2010.06.040.

Bashir, M. F., Ma, B., Bilal, K., \& B., Bashir, M. A., Tan, D., \& Bashir, M., (2020). Correlation between climate indicators and COVID-19 pandemic in New York, USA. Science of the Total Environment, 728, 138835. https://doi.org/10.1016/j.scitotenv.2020.138835.

Broomandi, P., Karaca, F., Nikfal, A., Jahanbakhshi, A., Tamjidi, M., \& Kim, J. R. (2020). Impact of COVID-19 event on the air quality in Iran. Aerosol and Air Quality Research, 20(8), 1793-1804. https ://doi.org/10.4209/aaqr.2020.05.0205.

Chow, R. (2020). A citizen's thoughts about COVID-19. The Lancet, 395(10231), e65. https://doi. org/10.1016/S0140-6736(20)30692-9.

COVID19 DELHI DATA. (2020). https://www.covid19india.org/state/DL.

Cui, J., Li, F., \& Shi, Z. L. (2019). Origin and evolution of pathogenic coronaviruses. Nature Reviews Microbiology, 17(3), 181-192. https://doi.org/10.1038/s41579-018-0118-9.

Delhi Location Map. (2020). https://www.mapsofindia.com/maps/delhi/delhilocation.htm.

Gautam, S. (2020). The influence of COVID-19 on air quality in India: A boon or inutile. Bulletin of Environmental Contamination and Toxicology, 104(6), 724-726. https://doi.org/10.1007/s00128-02002877-y.

Gautam, S., \& Hens, L. (2020a). COVID-19: Impact by and on the environment, health and economy. Environment, Development and Sustainability, 22(6), 4953-4954. https://doi.org/10.1007/s10668-02000818-7.

Gautam, S., \& Hens, L. (2020b). SARS-CoV-2 pandemic in India: What might we expect? Environment, Development and Sustainability, 22(5), 3867-3869. https://doi.org/10.1007/s10668-020-00739-5.

Gautam, S., \& Trivedi, U. (2020). Global implications of bio-aerosol in pandemic. Environment, Development and Sustainability, 22(5), 3861-3865. https://doi.org/10.1007/s10668-020-00704-2.

Gupta, S., Raghuwanshi, G. S., \& Chanda, A. (2020). Effect of weather on COVID-19 spread in the US: A prediction model for India in 2020. Science of the Total Environment, 728, 138860. https://doi. org/10.1016/j.scitotenv.2020.138860. 
Jahangiri, M., Jahangiri, M., \& Najafgholipour, M. (2020). The sensitivity and specificity analyses of ambient temperature and population size on the transmission rate of the novel coronavirus (COVID-19) in different provinces of Iran. Science of the Total Environment Journal, 728, 138872. https://doi. org/10.1016/j.scitotenv.2020.138872.

Jain, S., \& Sharma, T. (2020). Social and travel lockdown impact considering coronavirus disease (Covid19) on air quality in megacities of india: Present benefits, future challenges and way forward. Aerosol and Air Quality Research, 20(6), 1222-1236. https://doi.org/10.4209/aaqr.2020.04.0171.

Lai, C. C., Shih, T. P., Ko, W. C., Tang, H. J., \& Hsueh, P. R. (2020). Severe acute respiratory syndrome coronavirus 2 (SARS-CoV-2) and coronavirus disease-2019 (COVID-19): The epidemic and the challenges. International Journal of Antimicrobial Agents, 55(3), 105924. https://doi.org/10.1016/j.ijant imicag.2020.105924.

Li, Z., Meng, J., Zhou, L., Zhou, R., Fu, M., Wang, Y., et al. (2020). Impact of the COVID-19 event on the characteristics of atmospheric single particle in the Northern China. Aerosol and Air Quality Research, 20(8), 1716-1726. https://doi.org/10.4209/aaqr.2020.06.0321.

Lin, K., Yee-Tak Fong, D., Zhu, B., Karlberg, J. (2006). Environmental factors on the SARS epidemic: air temperature, passage of time and multiplicative effect of hospital infection. Epidemiology and Infection, 134 (2):223-230. https://doi.org/10.1017/S0950268805005054.

Menebo, M. M. (2020). Temperature and precipitation associate with Covid-19 new daily cases: A correlation study between weather and Covid-19 pandemic in Oslo Norway. Science Total Environment, 737, 139659. https://doi.org/10.1016/j.scitotenv.2020.139659.

Metya, A., Dagupta, P., Halder, S., Chakraborty, S., \& Tiwari, Y. K. (2020). COVID-19 lockdowns improve air quality in the South-East Asian regions, as seen by the remote sensing satellites. Aerosol and Air Quality Research, 20(8), 1772-1782. https://doi.org/10.4209/aaqr.2020.05.0240.

Nakada, L. Y. K., \& Urban, R. C. (2020). COVID-19 pandemic: Impacts on the air quality during the partial lockdown in São Paulo state Brazil. Science Total Environment, 730, 139087. https://doi.org/10.1016/j. scitotenv.2020.139087.

Rajput, H., Changotra, R., Rajput, P., Gautam, S., Gollakota, A. R. K., \& Arora, A. S. (2020). A shock like no other: Coronavirus rattles commodity markets. Environment Devlopment and Sustainability, 0123456789, 93. https://doi.org/10.1007/s10668-020-00934-4.

Şahin, M. (2020). Impact of weather on COVID-19 pandemic in Turkey. Science Total Environment, 728, 138810. https://doi.org/10.1016/j.scitotenv.2020.138810.

Shereen, M. A., Khan, S., Kazmi, A., Bashir, N., \& Siddique, R. (2020). COVID-19 infection: Origin, transmission, and characteristics of human coronaviruses. Journal of Advances Research, 24, 91-98. https ://doi.org/10.1016/j.jare.2020.03.005.

Shi, P., Dong, Y., Yan, H., Li, X., Zhao, C., Liu, W., et al. (2020), The impact of temperature and absolute humidity on the coronavirus disease 2019 (COVID-19) outbreak-evidence from China. medRxiv. https ://doi.org/10.1101/2020.03.22.20038919.

Sohrabi, C., Alsafi, Z., O’Neill, N., Khan, M., Kerwan, A., Al-Jabir, A., et al. (2020). World Health Organization declares global emergency: A review of the 2019 novel coronavirus (COVID-19). International Journal of Surgery, 76, 71-76. https://doi.org/10.1016/j.ijsu.2020.02.034.

Tosepu, R., Gunawan, J., Effendy, D. S., Ahmad, L. O. A. I., Lestari, H., Bahar, H., et al. (2020). Correlation between weather and Covid-19 pandemic in Jakarta Indonesia. Science Total Environment, 725, 138436. https://doi.org/10.1016/j.scitotenv.2020.138436.

Wunderground. (2020). New Delhi, Delhi, India Weather History. https://www.wunderground.com/history/ monthly/in/delhi/VIDD.

Zhang, J., Cui, K., Wang, Y.-F., Wu, J.-L., Huang, W.-S., Wan, S., et al. (2020). Impact of the COVID-19 event on air quality in central China. Aerosol and Air Quality Research, 20(5), 915-929. https://doi. org/10.4209/aaqr.2020.04.0150.

Zheng, Y. Y., Ma, Y. T., Zhang, J. Y., \& Xie, X. (2020). COVID-19 and the cardiovascular system. Nature Reviews Cardiology, 17(5), 259-260. https://doi.org/10.1038/s41569-020-0360-5.

Zhong, N. S., Zheng, B. J., Li, Y. M., Poon, L. L. M., Xie, Z. H., Chan, K. H., et al. (2003). Epidemiology and cause of severe acute respiratory syndrome (SARS) in Guangdong, People's Republic of China, in February, 2003. Lancet, 362(9393), 1353-1358. https://doi.org/10.1016/S0140-6736(03)14630-2.

Publisher's Note Springer Nature remains neutral with regard to jurisdictional claims in published maps and institutional affiliations. 


\section{Affiliations}

Amit Awasthi ${ }^{1}$ (D) Aditi Sharma ${ }^{2} \cdot$ Prabhjot Kaur $^{3} \cdot$ Balakrishnaiah Gugamsetty $^{4}$. Akshay Kumar ${ }^{5}$

1 Department of Physics, University of Petroleum and Energy Studies, Dehradun, UK 248007, India

2 Department of Petroleum Engineering and Earth Sciences, University of Petroleum and Energy Studies, Dehradun, UK, India

3 Department of Computer Science, Uttaranchal University, Dehradun, UK, India

4 Aerosol and Atmospheric Research Laboratory, Department of Physics, Sri Krishnadevaraya University, Anantapur, AP, India

5 Department of Nanotechnology, Sri Guru Granth Sahib World University Fatehgarh Sahib, Fatehgarh Sahib, Punjab, India 